\title{
Lapurdum
}

Euskal ikerketen aldizkaria | Revue d'études basques |

Revista de estudios vascos | Basque studies review

$19 \mid 2016$

Numéro XIX

\section{Soinu-artxiboek Ipar Euskal Herriko kantu monodikoaren ikerketa musikologikoari egin ekarpenak}

\section{Marie Hirigoyen Bidart}

\section{(2) OpenEdition}

1 Journals

\section{Édition électronique}

URL : https://journals.openedition.org/lapurdum/3398

DOI : 10.4000/lapurdum.3398

ISSN : 1965-0655

Éditeur

IKER

\section{Édition imprimée}

Date de publication : 1 janvier 2016

Pagination : 309-323

ISBN : 978-2-95534-134-6

ISSN : 1273-3830

\section{Référence électronique}

Marie Hirigoyen Bidart, «Soinu-artxiboek Ipar Euskal Herriko kantu monodikoaren ikerketa musikologikoari egin ekarpenak», Lapurdum [Linean], 19 | 2016, Sarean emana----an 01 janvier 2021, kontsultatu 03 septembre 2021. URL: http://journals.openedition.org/lapurdum/3398 ; DOI: https:// doi.org/10.4000/lapurdum.3398

Creative Commons - Attribution - Pas d'Utilisation Commerciale - Pas de Modification 4.0 International - CC BY-NC-ND 4.0 


\title{
Soinu-artxiboek Ipar Euskal Herriko kantu
} monodikoaren ikerketa musikologikoari egin ekarpenak

\author{
Marie HIRIGOYEN-BIDART \\ Toulouseko Unibertsitateko ikerlari asoziatua (LLA Creatis)
}

Euskal musikari buruz hainbat ikerketa egin dira XIX. mendetik egun arte, etnologoek, musikologoek, hizkuntzalariek edota musikazale soilek eginak. Kantuak funtsezko tokia du ikerketa horietan, frantsesez hainbat izen harturik ere : musique populaire basque, chanson basque, chanson populaire basque, Nouvelle Chanson basque, chant basque.

Idatzi gehienek Euskal Herriko boz praktika aipatzen dute, baina egile gehienak letretan edo etnologian berezituak direnez, usu, azterketa musikologikoa laburra izaten da. Adibide gisa, Francisque Michel filologoaren (1857), Jean Ithurriague filosofo/irakaslearen (1947), Pierre Navarre historialariaren (Narbaitz Kalonjearen, 1970) edo Belen Oronoz Antxordoki filologoaren (2000) argitalpenak aipa daitezke.

Bertze testu batzuk aipatzekoak dira, euskal literatura musikalari ekarpen handia egin diotelako; bertzeak bertze, José Antonio Arana Martijarenak (1976)1 edo Natalie Morel

1. Bere monografiaren zati handienean (Arana Martija 1976), euskal musika instrumentalaren historia kontatzen du; kantu herrikoiari buruzko zatian ez dago ez transkripziorik, ez grabaketarik, analisiaren sostengatzeko. Gehienetan, aitzinekoen hipotesiak berriz hartzen ditu, eguneratu ez kritikatu gabe. Gauza bera erran daiteke 1983an Etre basque testu kolektiboan argitaratu zuen La musique basque artikuluari buruz (Arana Martija 1983). 
310

Borotrarenak $(2003)^{2}$, baina ikerlan horien gaia ez da zuzenean hemen solasgai duguna.

Azkenik, idazle batzuek azterketa musikologiko sakonak proposatu dituzte, adibidez Charles Bordes (1899), Francisco Gascue (1913), Resurrección María de Azkue (1922-1923), Rodney Gallop (1928), Aita Donostia (1937) edo Aita Lerchundik (1947); baina haien lanak aski aspaldikoak dira. Alta bada, Béla Bartókek dioen bezala, « lehen folkloristek ezin zuten emaitza satisfagarririk lortu, ikuspuntu zientifikotik, funtsezko tresna bat eskas baitzuten : fonografoa ». Bilketa eta grabaketa teknikek etnomusikologoen lana errotik aldatu dute, 1960ko hamarkadaz geroztik: « horri esker, [bilketariek] ahal den erreprodukzio zehatzena ematen ahal dute, melodia bakoitzaren bat-batekoa » (Bartok, 1956).

Hain zuzen, 1990eko hamarkada arte itxoin behar izan da musikologia-ikerketa berriak sortzen ikusteko, non transkripzioa eta analisia molde modernoagoan planteatuak baitira. Aipa ditzagun, adibide gisa, Denis Laborde-n (Laborde 1992) edo Angélique Fulin-en lanak $^{3}$ (Fulin 2005).

Gure ustez, egun, euskal kantuen analisi musikologikoa egiteko bide bakarra lehen eskuko iturriak baliatzea da ; hots, grabaketak. Hortaz, hasteko, musika-datuen transkripzioan agertzen diren problematikak aipatu nahi genituzke, batez ere ahozko tradiziozko musikei dagokienez, azpimarratzeko zein zaila den grabaketa sortu aitzineko bilketekin (edo analisiari loturiko audio euskarririk ez duten azterketekin) fidatzea. Ondotik, eskura ditugun 1900 eta 1990 arteko soinu-artxiboen zerrenda ez osoa eginen dugu. Azkenik, ikerketa zientifikoetan soinu-artxiboak baliatzeak sortzen dituen problematika batzuk laburzki aipatuko ditugu, eta bukatzeko, euskal kantua aztertzeko soinu-artxiboak baliatzeak duen interesa oroitaraziko dugu.

\section{Datuen transkripzioa}

XIX. mendetik gaur arte, euskal kantuen bilketa anitz izan dira, batzuk ekimen ofizialekoak, bertzeak pertsonalak (Bagües 2002). Baina, argi da, ikerlari gisa, zaila dela bigarren eskuko iturri horiekin fidatzea.

Alabaina, ahozko tradizioko musika aztertzeak musika-entitate bat edo gehiago transkribatzea dakar. Musikaren parametro ezberdinak jaso behar dira, ahal den zehaztasunmailarekin - nahikeriaren eta transkribatzeko ditugun baliabideen arabera. Alta bada, JeanFrançois Dutertrek bilduma oro kontsultatzen duena abisatzen du : « jakin behar du liburu bat zabaltzen duela, eta beraz, idatzi gabeko kultura bat idatzizko kulturara pasatu duen lan bat, ahozko tradizioko artea solfeo eta literatura idazketara pasatu duen lan bat » (Dutertre 1991). Egun, badakigu pertzepzioak - Simha Aromek mezuaren deskodetzea deituko lukeenak (Arom 2002) - obrari buruzko iritziari, eta beraz, analisiari eragiten diola. Entzumena iduriz baino

2. Natalie Morel Borotra musikologoa euskal operari interesatzen zaio batez ere; hala ere, 2003an argitaratu bere tesian, folklore nozioa gisa interesgarrian lantzen du, ikuspuntu historikoarekin gehienbat.

3. Angélique Fulinek, 2005ean, Matalaz argitaratu zuen. Ikerketa, tradizioa eta sorkuntza uztartzen dituzten Xiberoko kantuaren praktika kolektiboari buruzko tailerren deskribapena da. 
konplexuagoa da. Alabaina, belarriak (kanpoko, arteko eta barneko belarriak), soinuak " mekanikoki » hartzeaz gain, burmuinak entzumen-seinalea hartzen du, eta beraz, kognitiboki tratatzen du (Botte 1989). Beraz, soinuak entzuteak erran nahi du soinu horiek hartzea eta burmuinak interpretatzea. Hemen, interpretazioa pertzepzio deitzen dugu. Errealitatearen irudikapen gisa, pertzepzioak ez du beti xuxen bat egiten iturriak igorri seinalearekin. Beraz, belarriak, burmuinaren bitartez, hartu seinalea alda dezake: « adaptation de l'intensité à l'entrée de l'oreille moyenne; ajustement de la sélectivité fréquentielle de l'oreille interne; focalisation de l'écoute au niveau central, pour extraire du signal sonore global les parties significatives pour le sujet » (Castellengo 1994).

Horrez gain, nahita ala oharkabean, transkribatzen duenak hartu duen seinalea bere nortasunaren arabera ere alda dezake : guretzat zentzua duena atxikitzen dugu. Baina, XX. mende erdira arte, ahozko tradizioko musika bilketariak ez ziren fenomeno horretara sentsibilizatuak, eta beraz, hain segur, ezberdintasun handiak ziren hartu seinalearen eta transkripzio/deskribapen/analisiaren artean. Oro har, erran daiteke bilketa bilketariaren kulturaren araberakoa dela. Eta bilketari gehienak musika sabantaren arlokoak zirenez, pentsa daiteke horrek eragina(k) izan d(it)uela egun eskura ditugun transkripzioetan. Denis Labordek dioen bezala, diktaketa bidezko transkripzio guzietan dagoen arbitrariotasuna maiz ahanzten dugu, « laburki errateko: transkripzioa ahalbidetu duen solas-egoera ezabatzen dugu eta musikologoaren proiektua ahazten dugu, alta diktaketan bere hautuak orientatu ditu » (Laborde 1996).

Azkenik, transkripzioari berari dagokionez (edo, Simha Aromen hitzetan, mezuaren birkodetzeari dagokionez, 2002), kodeak atzeman (hautatu) behar dira, entzun soinuak ahal bezain ongi irudikatzeko. Baina, alde batetik, Udo Willek oroitarazten digun bezala, « mendebaldeko musika-notazioa bere musikaren baitan sortu eta garatu denez, bortxaz, mendebaldekoak ez diren musiken alderdi batzuk deskribatzeko baliatzen bada, arazoak sortzen dira (Will 1999). Alabaina, idazketa-sistema hori musika sabantari egokitua zaio (horrentzat sortua baita). Bertzalde, eskura ditugun kode grafikoak eta soinu-errealitatea bat etorrarazteko zailtasuna ez dagokie mendebaldekoak ez diren musikei bakarrik, baizik eta ahozko tradizioko musika guziei, bi arrazoi nagusi direla-eta : sorkuntza eta praktika prozesuak ez dakar idazketaren urratsik, eta musika-hizkera ez da beti bera (tenperamentua, neurria, eskala). Beraz, ahozkoaren eta idatzizkoaren arteko egokitzapena lausoa da. Judit Frigyesik honela azaltzen du: lausotasun hori ahozko esperientziaren dimentsio-aniztasunaren adibidez, hizkuntzari dagokionez, ahoskera, jarioa, doinua, bozaren kalitatea, jestuak, gorputzmugimenduak etab. - eta idatzizkoaren dimentsio-bakartasunaren arteko kontraerranetik dator (Frigyesi 1999). Ahozko gertakari bat idatziz eman nahi duen orok problematika horri aurre egin behar dio. Horri gehitu behar zaizkio, ahozko tradizioko kantuak aldakorrak 
direla (kantu berak beti hainbat bertsio ditu $)^{4}$ eta soinu-ekoizpen bakoitza berdingabea dela: transkripzioa egiten duenak, beraz, soinu-irudikapen (eta irudikapen grafiko) anitzak ditu aitzinean.

Transkripzio bidez egin diren bilketa guziek errepertorio neurrigabea babestea ahalbidetu dute. Transkripzio deskriptiboetan ${ }^{5}$ edo partitura emikoetan, ahozko tradizioko kultura horretan murgildua den norbaitek notazioa baliatzen ahal du bilatzeko, atzemateko, baliatzeko, « birsortzeko »,..., xede artistiko edo/eta kulturalekin. Baina XX. mende osoan zehar euskal kantua landu duten musikologoen zailtasunak ezin dira gutietsi (diktaketa bidezko transkripzioa, pertzepzioak eragin problemak, musika sabantaren idazketa-arauei erreferentzia - nahita ala nahigabe - , idazketa-kode desegokiak, etab.). Horrek, dudarik gabe, badu eraginik beren transkripzioetan, eta beraz, beren analisietan. Beraz, gure ustez, analisiari lotu grabaketarik gabe, zaila da XX. mendean musikologoek argitaratu transkripzioak kontuan hartzea : baliatu zeinuak ezin ditugu interpretatu soinu-materiala bera entzun gabe.

\section{Eskura ditugun artxiboen deskribapena (1900-1990)}

Zati honen xedea 1900 eta 1990 artean grabatu soinu artxiboen zerrenda ez osoa egitea da.

\subsection{0: Dr Azoulay eta Pariseko Antropologia Sozietatea}

Dakigunez, Ipar Euskal Herriari buruzko euskarazko lehen soinu iturriak 1900. urtekoak dira, eta Léon Azoulay doktoreak bildu zituen, Pariseko Antropologia Sozietateak galdeginik, Pariseko erakusketa unibertsala kari. Bost hilabete inguruz, erakusketaren baitan eta erakusketatik kanpo, Azoulay doktoreak laurehun fonograma baino gehiago bildu zituen, inkesta linguistiko baten baitan. Orduko inbentarioak jendaki hauek biltzen ditu:

- Ipar Afrikan: berberrak, arabiarrak.

- Saharaz hegoaldeko Afrikan: senegaldarrak, dahomeytarrak, nigeriarrak, zanzibartarrak, Madagaskarreko eta Komore Handiko jendakiak.

- Asian: txinatarrak, japoniarrak, laostarrak, tonkindarrak, siamdarrak, zingaliarrak, indiarrak, Turkestaneko jendakiak, pertsiarrak, armeniarrak, kaukasiarrak, georgiarrak, siriarrak.

- Europan: ruteniarrak, jugoslaviarrak, txekiarrak, turkiarrak, Konstantinoplako

4. Lerchundiren ustez, « les timbres populaires ne doivent jamais être considérés comme définitivement fixés. [...] ce serait faire preuve d'étroitesse d'esprit et d'ignorance totale des lois du folklore musical que de vouloir imposer de force, pour chaque chant, une version unique, officielle. Un auteur de recueil noté doit savoir que la pratique du peuple déborde à chaque instant la notation musicale. Celle-ci n'a qu'une valeur provisoire et ne représente qu'un moment plus ou moins long de la trajectoire évolutive des mélodies populaires » (Lerchundi 1947).

5. Notazio preskriptiboa (hau da, musikariek ekoitzi behar dituzten soinuak agintzen dituena) ez bezala, transkripzio deskriptiboa notazioaren azpisail bat da, musika biziaren estenografia (Ellingson 1992). 
juduak, magiarrak, finlandiarrak, letoniarrak, suediarrak, norvegiarrak, islandiarrak, alemaniarrak, frantsesak, italiarrak, espainiarrak.

Grabaketa horietako batzuk erranak dira ; bertzeak, ahots-musikak edo/eta instrumentu-musikak. Azoulay doktoreak galdeginik, Antropologia Sozietateak, 1900. urtean, museo fonografiko baten sortzea bozkatu zuen, grabaketa horiek eta ondotik eredu berean oinarriturik eginen zirenak biltzeko (Azoulay 1901). Egun, soinu-artxibo horiek Etnomusikologiako Ikerketa Zentroan daude (Laboratoire d'Ethnologie et de Sociologie Comparative - UMR 7186)6.

Euskal Herriari dagokionez, item hauek agertzen dira (Azoulay 1902):

85 - 85 bis. Jondoni Joaniren ebanj., 20. kap., irakurria eta silabizatua (xiberotarrez, Maule)

89. Haur. Barre. irakurria (gipuzkoarrez, Donostia).

86. Kantu herrik.: L'oiseau, kantatua eta irakurria (xiberotarrez, Maule).

87. _ maitasunezko kantua (id.).

88. _ La belle héritière (xiberotarrez).

90. Kantu herrik.: Les trois demoiselles de Saint-Sébastien, errana, eta elkarrizketa (gipuzkoarrez, Donostia eta Bilbo).

91. Kantu herrik.: Les trois demoiselles de Saint-Sébastien, kantatua. Euskal gerla-oihua, fonogramaren bukaeran (gipuzkoarrez, Donostia). Donostia)

92. Maitasun kantu herrik: Eriguentan bachubec, eta satirikoa: Pelio Josepe (gipuzkoarrez,

Grabaketa horiek Vinson jaunari esker egin ziren, ekialdeko hizkuntzen eskolan irakasle izateaz gain, Euskal Ikasketen Kongresuko lehendakari baitzen. Gure ikergaiari dagokionez, egun, Etnomusikologiako Ikerketa Zentroak hiru zilindro hauen bertsio numerikoa eskura ematen du:

87: Maitia nun zira maitasun kantua, gizon batek emana (1'25 min.), Frantzian, euskaraz, xiberotarrez.

88: Prima eijerra maitasun kantua, gizon batek emana (2'21 min.), Frantzian, euskaraz, xiberotarrez.

92_01: Donostiako hiru damatxo kantu satirikoa, emazte batek emana (2'44 min.), Espainian, euskaraz, gipuzkoarrez.

92_02: Eriguentan bachubec maitasun kantua eta Pelio Josepe kantu satirikoa, emazte batek emanak (1'38 min.), Espainian, euskaraz, gipuzkoarrez.

6. CREM zentroak dokumentu-funts zabala kudeatzen du (musika-artxiboak eta liburuak), ondare balio gorenekoa, eta nazioarteko hartzaileek kontsultatua. Bertzalde, disko-bilduma handia argitaratu du. 


\subsection{3: Rudolf Trebitsch eta Phonogrammarchiv}

Dakigunez, Ipar Euskal Herriko bigarren soinu corpus zaharrena 1913koa da, eta Rudolf Trebitschek osatua da. Dokumentu horiek Vienako Phonogrammarchiven bilduak dira $^{7}$

Rudolf Trebitsch (1876-1918) Austriako mediku eta etnologoa zen. XX. mende hastapenean, zenbait inkesta etnografiko egin zituen Groenlandian (1906), herri zeltetan (1907-1909) eta Euskal Herrian (1913), Vienako Phonogrammarchiveko grabaketa materialarekin ${ }^{8}$. Bere ikerketetan, Rudolf Trebitschek grabaketei informatzaile bakoitzaren datuak, kontatu ipuinen (edo kantuen) laburpenak, testuen notazioa eta frantsesezko itzulpena gehitu zizkien. Musikaren ikuspuntutik, artxibo horien berezitasuna Ipar Euskal Herriko berezko testuinguruan grabatuak izan diren lehen iturriak izatea da. Alabaina, 1900. urtean, Pariseko Erakusketa Unibertsalaren antolatzaileek Frantziako eta munduko eskualdeetako hainbat jende trenez jinarazi zituzten - hizkuntza eta kultura baten ordezkari gisa -, Parisen grabatzeko. Rudolf Trebitsch, aldiz, « lekura » joan zen, bertzearen memoria ${ }^{9}$ biltzera.

Eresbil euskal musika artxiboen zentroak helarazi datuen arabera, hirurogeita hamalau Edison zilindro lirateke, bakoitza bi minutu ingurukoa, Euskal Herriari buruz. Dokumentu horietako batzuk 2003an argitaratu ziren, The Collections of Rudolf Trebitsch ${ }^{10}$ sailaren hirugarren atal gisa. Beraz, egun, Euskal Herriari buruzko hirurogeita sei grabaketa eskura ditugu : lekukotasun, kontakizun, poesia eta gisa horretako anitz ; lau instrumentu-item eta hamabi kantu (item batzuetan kantu labur zenbait badira) -, eta horietatik zortzi Ipar Euskal Herrian grabatuak.

Hona hemen kantuen zerrenda ${ }^{11}$ :

2215: Santi Agera, gizon batek emana (1'50 min.),

2236: Xarmangarria zera, gizon batek emana (1'50 min.),

2237: Ume eder bat, gizon batek emana (1'51 min.).

Hego Euskal Herrian grabatuak,

2179: Pleñitzen naiz biotzetik, gizon batek emana (2'16 min.),

2180: Baionako Patroina, gizon batek emana (1'22 min.),

2182: Laphurdi huntan bada bertsulari anhitz (0'34 min.) ; Frantziako errege banintz (0’48 min.) ; Mundu hau bethia da (0'28 min.), gizon batek emanak,

7. Bertze zilindro batzuk ba omen dira Berlineko Phonogrammarchiven.

8. Phonogrammarchiv diziplina anitzeko soinu-artxiboen funtsa da, lehen mailako iturri akustikoen grabaketa egiten eta errazten duena, eta ikerketarako biltzen dituena, muga geografikorik gabe (Parejo-Coudert 2002).

9. Bistan da, Jean-Loic Le Quellecek zuzendu eta 1991n Niorten argitaratu lanaren izenburuari erreferentzia egiten diogu (Geste Éditions, Collection Modal).

10. The Collections of Rudolf Trebitsch. Basque recordings 1913', Sound Documents from the Phonogrammarchiv of the Austrian Academy of Sciences. The Complete Historical Collections 1899-1950; Series 5/3. Vienne : Österreichischen Akademie der Wissenschaften. 2003. 2 disko + CD-ROM $1,133+$ liburu 1,71 .

11. Trebitschen ortografia dugu hemen baliatzen eta jatorrizko sailkapena. 
2199: Txori erresiñola (0’48 min.) ; Jaiki, jaiki (0’44 min.) ; Benedika dakiola (0’36 min.), gizon batek emanak,

2202: Agota (1'50 min.), emazte batek emana,

Ipar Euskal Herrian grabatuak.

\section{3. 1915 - 1918 : Alemaniako euskal presoen grabaketak}

1915 eta 1918 artean, hogeita hamar bat zientifiko aleman famatuk (antropologo, hizkuntzalari eta musikologo) Alemaniako 175 preso kanpamenduetatik batzuk bisitatu omen zituzten. Bisita horietan, grabaketak ere egin zituzten : talde etniko anitz agertzen dira, gehienbat Europako herrietakoak eta beren itsasoz haraindiko lurralde ohietakoak, eta horien artean euskaldunak. Euskal Kultur Erakundeak helarazi informazioen arabera funts horren zaintzaile baita, Berlineko Humbold Unibertsitateko Museo Etnografikoarekin 2014an abiatu partaidetzari esker -, funts horretan 35 soinu-fitxategi daude, orotara oren bat inguru irauten dutenak. 71 kantu zerrendatuak izan dira, gehienak xiberotarrak : 66 kantu " tradizional » direlakoak eta 5 erlisionezko kantika. Maider Bedaxagaren arabera, zilindroek 2 minutu eginen omen lukete, eta bertset bat edo bi dute kantatzen kantariek. Ez dugu sekulan kantu bat osorik. Euskaldun horiek iduriz bi aldiz grabatuak izan ziren (1916 eta 1918), Manheim eta Rottleberodeko presondegietan ${ }^{12}$. Grabaketa batzuentzat, Berlineko Humboldt Unibertsitateak informazio osagarri xeheak emanak ditu.

\subsection{7 : Hubert Pernot eta Archives de la Parole artxiboak}

1927ko soinu corpusa Hubert Pernotek Pariseko Archives de la Parole artxiboetako « laborategian » egin grabaketez osatua da.

1911 ko ekainaren 3an, Ferdinand Brunot (1860-1938) gramatikalari eta frantses hizkuntzaren historialariak Archives de la Parole artxiboak estreinatu zituen. Sorbonaren baitan sortu zituen, Emile Pathé industrialariaren laguntzarekin. Pascal Cordereixek dioenez, artxibo horien xedea fonografoari esker ahozko hizkuntza grabatzea, ikertzea eta kontserbatzea da. Baina, Austriako Vienako Phonogrammarchiv bezala, Archives de la Parole artxiboen berezitasun handia soinu-artxibo propioak ekoiztea, sortzea izanen zen (Cordereix 2005). Laster, Ferdinand Brunotek Atlas linguistique phonographique des patois et dialectes de France ${ }^{13}$ atlasa sortzeko proiektua abiatu zuen. Soinu-bilketetan, kontakizunak, elkarrizketak eta kantuak grabatu zituen, Ardennes franko-belgiarren eskualdean (1912), eta Berry eta Limousin eskualdeetan (1913). 1924tik goiti, Musée de la Parole erakustokiak aktibitate eremua zabaldu zuen, bilketa folkloriko eta etnografikoak eginez, eta bere bildumak artxibo musikalagoz osatuz: « Hala, hizkuntzalaritzatik musika-folklore-rako bihurgunea arras nabarmena da » (Cordereix 2005).

12. 2015eko maiatzaren 12 ko elkarrizketatik hartu solasak.

13. Nicolas Verduren arabera, Bibliothèque Nationale de Franceko soinu corpus inportanteena munduko dialekto eta folkloreen grabaketak litaizke, eta Franziarenak partikulazki (Verdure 2006). 
Hubert Pernot (1870-1946) formakuntzaz helenista zen, greko modernoan berezitua. Archives de la Paroles artxiboen buru izan zen Jean Poirot fonetikalariaren ondotik, eta gero, Musée de la Parole et du Geste ${ }^{14}$ erakustokiko buru, 1924tik 1931 arte. Hainbat lekuko inkesta egin zituen (bilduma folklorikoak), atzerrian : Errumanian (1928), Txekoslovakian (1929) eta Grezian (1930). Frantziako eta atzerriko tokiko mintzairen eta dialektoen soinu-artxiboak osatzeko, Archives de la Parole artxiboetako « laborategian » grabaketak egin zituzten: Korsikako, Pikardiako, Euskal Herriko tokiko mintzairak, baita bengalia, txinatarra, persiarra... (Verdure 2006).

Euskal Herriari buruzko 1927ko binilozko bi disko eskura ditugu ${ }^{15}$, biak Hubert Pernotek grabatuak:

1. Diskoa: A aldea: Hego Euskal Herriko euskarazko kontakizuna [inprobisazioa] (2'57) / B aldea: Kontakizun beraren laburpena, gazteleraz eta frantsesez (2'45). Informatzailea: M. Juan Acordagoicoechea. Biltzailea: Hubert Pernot. Data: 1927ko ekainaren 14a. Argitaratzailea: Université de Paris, Archives de la Parole (Paris).

2. Diskoa: A aldea: Xiberotarrezko predikua (3'04) / B aldea: Le barde Etchahun et le barde Otchaldé (Etchahun eta Otchalde); Urzo churia: xiberotarrezko kantu herrikoiak (2'49). Informatzailea: Jean Larrasquet-Prioria apeza. Biltzailea: Hubert Pernot. Data: 1927ko martxoaren 15a. Argitaratzailea: Université de Paris, La Sorbonne, Archives de la Parole (Paris).

2.5. 1947: Claudie Marcel Dubois eta Musée des Arts et Traditions Populaires erakustokia

1947ko grabaketak Musée National des Arts et Traditions Populaires erakustokiko funtsekoak dira. Claudie Marcel-Duboisek egin zituen, maiz Marie-Marguerite PichonnetAndralekin, lekuko misio etnologikoen karietara.

Musée National des Arts et Traditions Populaires erakustokiak, 1937an sortu zenetik, material-bildumez gain, «musika-etnografia zerbitzua» ere bazuen. 1950eko hamarkadan, «etnomusikologia departamentua» bilakatu zen, eta egun «musikaren departamentua» deitzen da. Departamentu horren xedea musika-etnografia bildumak «biltzea, kontserbatzea eta sortzea» zen. Hastapeneko fonotekan, ondoren soinu-artxiboen zentroa bilakatuko zenean,

14. Pascal Cordereixen iritziz, hemen, « jestuaren » nozioa zinema-artxiboak soinu-artxiboei eransteko proiektuari dagokio (Cordereix 2005).

15. Gallica artxibategi numerikoa, Bibliothèque Nationale de France. URL: http://gallica.bnf.fr/Sea $\mathrm{rch}$ ?ArianeWireIndex $=$ index $\&$ lang $=F R \& f$ _typedoc $=$ audio $\& \mathrm{q}=$ basque $\& \mathrm{p}=1 \& \mathrm{zf}$ _creator $=$ Pernot \%2C+Hubert+.+\%C3\%89diteur+scientifique+\%281870-1946\%29, 2012ko martxoaren 27an kontsultatua. 
bi bilduma mota zeuden: « argitaragabeak » edo grabaketa originalak ${ }^{16}$, eta « argitaratuak », publikoak zirenak (merkataritza-labelek ekoitziak edo irratsaio edo kontzertuen grabaketak). Claudie Marcel-Duboisek dioenez, misio horiek inkestak musikaren, hizkuntzalaritzaren eta etnologiaren ikuspuntutik pentsatzen hasten ziren garaian egin ziren, langile berezituekin eta grabaketarako materialarekin (Marcel-Dubois 2003).

Euskal Herriari dagokion funtsak hamazazpi inkesta biltzen ditu (1947-1984), batez ere bertsulariei, kantuari, maskaradei eta pastoralei buruzkoak. Grabaketak Baxenabarren, Xiberoan, Bizkaian baita Parisen ere egin ziren, hainbat gertakariren karietara ${ }^{17}$. Zaharrenak 1947an Claudie Marcel-Duboisek Donibane Garazin (Baxenabarre), Saran eta Arrangoitzen (Lapurdi), Garindainen eta Alozen (Xiberoa) egin inkestakoak dira. Inkesta horretan, kantari eta musikari anitzen errepertorioa bildu zuen. Claudie Marcel-Duboisek 216 kantu, hogei bat instrumentu-doinu, berrogeita hamar bat hauta kantu, leloak, ipuinak, oihuak etab bildu zituen $^{18}$ (Perre \& Le Gonidec 2013).

Claudie Marcel-Dubois eta Marie-Marguerite Andralek Euskal Herriari buruzko bertze grabaketa batzuk egin zituzten, 1953an - Entretien avec le txülülari Ximun Patalagoity - , 1958an - Concours de bertsulari et chants basques enregistrés à Paris -, eta 1973an Enquête ethnomusicologique en Pyrénées-Atlantiques réalisée dans le cadre d'une mission CNRSATP. Bertzalde, bilduma-kopiak ere badaude, hala nola Bernard Duhourcau (1959), JeanMichel Guilcher (1963, 1964, 1967), José Luis Achotegui (1974-1975) edo Denis eta Martine Laborderenak (1982-1983). Azkenik, funts horretan pastorala batzuk $(1963,1964,1967)$ eta maskaradak (1968) ere badira. 2011 z geroztik, grabaketa horien kopia numerikoa kontsulta daiteke Baionako eta Euskal Herriko artxibo poloan, 2007ko abenduan Pirinio Atlantikoetako Departamenduarekin eta 2013tik Marseillan dagoen Musée des Civilisations de l'Europe et de la Méditerranée erakustokiarekin (MNATP ohiarekin) partaidetza-hitzarmena izenpetu baitzen.

\subsection{0ko hamarkada: Ximun Haranen grabaketak}

1960ko hamarkadan egin grabaketak Ximun Haranen funtsekoak dira. Egun, Mauleko (Xiberoa) Sü Azia elkartean daude.

Ximun Haran (1928-2013) Arrangoitzen sortu zen. Farmazialaria zen, pilotaria, eta «

161939 eta 1989 artean bilduak izan ziren, eta hainbat euskarritan banatuak dira: bertzeak bertze, zaharrenak pyral zuzeneko grabaketako diskoetan (39-52 urteetan), eta berrienak fitxategi numerikoetan. Gehien-gehienak zinta magnetikoetan grabatuak dira. Orotara, 45.000 item (edo « zati ») dira. Zientziaren eta ondarearen ikuspunturik ohargarrienak Frantziako eskualdeei buruzkoak (Bretainia, Auvernia...) eta Frantziako kulturakoak edo jendakikoak izan dako herriei buruzkoak (Antillak, Belgika, Kanada frantsesa, Louisiana, etab..) dira.

17 Pirinio Atlantikoetako departamendu-artxiboak. URL: http://earchives.cg64.fr/ead. html?id=FRAD064_5NUM1, 2012ko martxoaren 26an kontsultatua.

18. Misio hori Euskal Museoaren eta zuzendari zuen Boisel komandantearen laguntzaz egin zen. Gavel irakasleak, okzitanieran, gazteleran eta euskaran berezitu hizkuntzalariak, inkesta-puntuen hizkuntzalaritza-zuzendaritza eta antolaketa beregain hartu zituen (Marcel-Dubois 2003). 
abertzale Enbata » mugimenduaren sortzaileetakoa. Harekin mintzatu ginelarik ${ }^{19}$, grabaketak zein testuingurutan egin zituen kontatu zigun.

Ximun Haran gaztea zelarik, Xiberora joaten zen pilotan aritzera (Barkoxera, Urdiñarbera, etab.). Partiden ondotik, jendea kantuz entzuten zuen. Eta Xiberoako kantuek bereziki hunkitzen zuten - haren ustez, Lapurdikoez bestelakoak baitziren.

« Erran gabe doa garai hartan [1960ko hamarkadan] pilotariak «pertsonaiak» zirela, [... jendeek konfiantza osoa ematen ziguten, eta beraz, partiden ondotik, maiz, ez ginen autoz eskapatzen, elkarrekin egoten ginen, jaten genuen, tipoak kantatzen entzuten genituen ».

Bere lagun batek, Mixel Eppherrek erraten zion, adibidez, jende hau kantu hura zekien bakarra zela : " hilko delarik, ahantziko da ». Ximun Haran harritu zen: " grabatu behar dut ». Beraz, Alemaniara joan zen aitarekin, grabagailu baten erosteko: « [...] garai hartan, zinta-grabaketarik ez zen ». Hainbat zailtasun gainditu eta mugen pasatzeko zenbait isun pagatu eta, baimen ofiziala lortu zuen, « kultur xedeko inportazioa » egiteko. Orduz geroz, Ximun Haranek grabaketa anitz egin ahal izan zituen, libroki. Harekin besta egin ohi zuten kantariak deitzen zituen, Lechardoy lagun xiberotarrarekin (Barkoxekoa), apairuen ondotik grabatzeko. Alkoholak lagundurik, kantariek hobe egiten zioten aurre grabagailu berriari: « gutienez gauerdi arte beha egon behar zen, edan zezaten eta oro [...]; hastapenean, biziki zaila izan zen ». Ondotik, Ximun Haranek disko fabrika bati dei egin zion, egiten ari zen grabaketa ugariak zabaltzeko. Horrela sortu zen Club du Disque basque delakoa. Geroago, erregularki Belokeko abadiara joaten zen, lauzpabost fraiderengana, euskal kantuaren « aditu eta zaleak » baitziren, zintak nola muntatu haiekin erabakitzeko: « haiek naute lagundu hautatzen, Belokeko fraideek. [...] segurtamen bermea ematen zidan ». Euskal Museoan gela bat bazuen beretzat, Jean Ithurriague zuzendariak eskura emana, muntaketen egiteko. Zintak bukatu eta, Ximun Haranek Parisera igortzen zituen, diskoan argitaratzeko. Berak dioenez, grabaketa horiek arrakasta ukan zuten, baina ez aski garatzeko. Hogeita hamar bat urte berantago, hots 1990ko hamarkada inguruan, Ximun Haranek zinta original guziak euskal kulturaren eta hizkuntzaren aldeko Sü Azia elkarteari eman zizkion, Marcel Bedaxagarren bitartez, numeriza zitzaten (DAT kasetetan). Alabaina, Bedaxagar, elkarteak 1980ko hamarkadan egin kantu xiberotarren bilketa izigarri baten arduraduna zen. Funts zaharragoen numerizatzea proiektuaren parte zen.

Egun Sü Azian dagoen Ximun Haranen funtsa hogeita bi DAT kasetetan banatua da (hots, orotara, kasik berrogei oren) ${ }^{20}$. Kantuak (txapelketa, lekuko inkesta ${ }^{21}$, kontzertu/ kantaldi), bertsuak, pastoralak, antzerki-lanak, irratsaioak, erlisionezko musika, mintzaldiak, politika edo kultura arloko bilkura eta eztabaidak, lekukotasunak, etab. biltzen ditu. Kantuak

19. Ondoko aipu guziak 2012ko urtarrilaren 2lean izan genuen elkarrizketako zatiak dira.

20. DAT kaseteak 300etik 322ra zenbakituak dira. Datuak euskarri informatikora pasatu ditugu, Sü Azia elkartearen, Euskal Kultur Erakundearen, Xiberoko Herri Elkargoaren eta Pirinio Atlantikoetako Kontseilu Nagusiaren arteko lankidetzari esker.

21. Pierre Cherbero Lohidoy, Pierre Oyhanart Tzapelo, Jean-Pierre Bordaleku, Bidegai Mohorade, Queheillechipy, Jeannot Duleau Hagola, Laurent Loyatho, Michel Labéguerie, Robles familia, Petti Phoi Queheille, Anne-Marie Achigar, Agnès Aguer Cocosteguy, Junes Chuburu, Alexis Etxekopar Attuli, Irigoien, etab. 
toki garrantzitsua du funts horretan. Grabaketa gehienak Ipar Euskal Herrian eginak izan dira, baina Hego Euskal Herriko grabaketa zenbait ere bada.

\subsection{0eko hamarkada: Marcel Bedaxagar eta Sü Azia elkartea}

1980ko hamarkada hondarrean, «Collectage - Archivage - Transmission du chant souletin »izeneko proiektua sortu zen Xiberoan, tokiko garapen proiektu baten baitan. Proiektu horrek kultura eta nortasuna argitan ezartzen zituen, abantaila gisa, ekimenen sortzeko eta laguntzeko pizgarri gisa. Mauleko Sü Azia aholkatzeko, aditu talde bat osatu zuten ; hain zuzen, B. Achiary, J. Haritschelhar eta Ph. Oyhamburu jaunak. Proiektu horrek, 1988an, Frantziako Kultura Ministerioko Musika Tradizionalen Departamentuaren laguntza izan zuen, Delannoy jaunak aditu-txosten bat egin baitzuen, A.D.A.M.P.A.ko zuzendari Saury jaunaren laguntzarekin.

Proiektu horrek Kultura Ministerioaren manuekin bat egiten zuen, eta hiru xederen inguruan antolatua zen, izenak dioen bezala. Bilketa Marcel Bedaxagarrek egin zuen, 1990eko hamarkada hastapenean. 211 DAT kaseteko (bakoitza 120 minutuko) corpusa osatu zuen ; hots, orotara, soinu argitaragabez osatu laurehun oren baino gehiago. Berak egin grabaketez gain, corpusak bertze batzuek bildu zinten kopiak ere baditu (1960ko hamarkadako Ximun Haranenak, 1980ko hamarkadako Diddue Eppherrenak,...). Kantuak dira gehienbat, mota guzietakoak (kontzertuak, gaualdiak, bertsulariak, mezak, pastoralak, maskaradak edo grabaketa informalagoak,...). Bertzalde, lekukotasunak, kontakizunak, bilkurak eta irratsaioak ere badaude. Artxibatzeari dagokionez, Baionako IUT institutuak proiektuarekin bat egin zuen. Hala ere, orduko baliabide informatikoak mugatuak zirenez, lan-urrats hori ezin izan zen bururatu. Azkenik, agerian emateko ekintza soil batzuk izan ziren :

- Pierre Bordaçarre Etchahun (Etchahun-Iruri, 1908-1979) xiberotarraren kantu batzuk biltzen dituen diskoa, Elkar diskoetxeak argitaratua.

- Soinu-artxibo batzuk, Euskal Kultur Erakundearen Kantuketan - L’univers du chant basque erakusketan baliatuak.

Guhaurrek funts hori landu dugu, eta, bertzeak bertze, 1990eko hamarkadan egin lanak zerrendatu. Alabaina, Xiberoak ondare immateriala salbatzeko eta kontserbatzeko proiektua abiatu da, Sü Aziak eskura duen ondare multzoa salbatzeko, baliagarri egiteko eta ikerlari eta jende ororen eskura emateko ${ }^{22}$. Horren karietara, datuak euskarri numerikora pasatzea bukatu dugu, 2009an. Artxibatzea Maddi Oihenartek egin du, eta bururatu berri $\mathrm{du}^{23}$.

22. Pirinio Atlantikoetako Kontseilu Nagusiak, Xiberoko Herri Elkargoak, Euskal Kultur Erakundeak eta Sü Azia elkarteak hitzarmen bat izenpetu zuten, jada egin lana kontuan hartuz, egin beharreko lanaren zehazteko eta balioesteko. Horri buruz, mila esker Pascal Gaillardi (irakasle/ ikerlaria, Toulouse unibertsitateko Jacques-Lordat laborategia, Toulouseko Institut des Sciences du Cerveau institutua), proiektuan zehar eman aholkuengatik.

23. Soinu argitaragabeen artxibatzeko datu-base bat sortua izan da, Marie-Laure Maravalen laguntzarekin (Toulouse le Mirail unibertsitatea - Sygne enpresa), doktoretzaren eta Sü Azia elkartea-rendako egin lanaren baitan. 


\section{Soinu-artxiboen ekarpena}

Beraz, XX. mende osoan zehar, soinu-artxiboak eraiki dira, bertzeak bertze Ipar Euskal Herriko boz praktika monodikoaren egiazko lekukotasuna eskura ematen digutenak.

Baina, zer erran grabaketaz?

Hasteko, grabaketa jende edo talde baten erabaki anitzen ondorioa da : nor grabatu? non? zein errepertoriori buruz? zein materialekin? zein testuingurutan? soinu-hartze guziak atxiki, edo batzuk hautatu? etab. Galdera horiei arraposturik eman gabe, ezin da jakin grabatu kantua garai baten, praktika baten, lurralde baten, hizkuntza baten eta abarren adierazgarri den. Alta, grabaketei lotu informazioek hutsune anitz dute. Gure kasuan, eskura ditugun grabaketak, beharbada, historiako garai ezberdinetan egiten zen guziaren txantiloi ttipi bat baizik ez dira. Horrez gain, kantari batzuk beren jatorrizko adierazpen-testuingurutik kanpo grabatuak izan dira (Pariseko erakusketa unibertsalean 1900ean, Pathé estudioetan 1927an), eta beraz, grabaketen egokitasuna dudazkoa dela pentsa daiteke. Azkenik, euskal musika musika bizia denez, eta beraz, etengabe aldatzen denez, kantu-emanaldi bakoitza paregabea da; ondorioz, zaila da grabaketa praktika baten edo kantari baten isla sistematiko gisa hartzea. Beraz, analisia oro kontuan hartu musika-iturrien hautuaren araberakoa da.

Bertzalde, grabaketen kalitatea ez da beti aski ona datuak zehazki aztertzeko. Batzuetan, kantuaren guti gorabeherako irudikapena baizik ez dugu (adibidez, goratasunaz ohartzeko). Alta, dudarik gabe, grabaketaren kalitatea zenbat eta hobea, orduan eta azterketa-bide gehiago du ikerlariak ; eta kalitatea gehienbat grabaketa-urtearen araberakoa da, eta beraz, biltzeko, babesteko eta kontserbatzeko baliatu materialaren araberakoa.

Azkenik, Denis Laborden ustez, transkripzioa bezala, grabaketa ez da kantua ; soinuerrealitatearen irudikapena da, eta ez soinu-errealitatea bera: "Magnetofonoak hartu kantua [...] komunikazio-egoera guziz konplexu baten lagin-hartzea baizik ez da : ele-ekintzaren miniaturizatzea, nolabait errateko. Beraz, magnetofonoari esker ematen den objektua ez da sekulan barne hartzen duen gertakariaren emaitza bat baizik » (Laborde 1992). Beraz, ez transkripzioak ${ }^{24}$, ez grabaketak ezin dute kantariaren eta entzulearen artean sortzen den komunikazio-harremana den bezala eman. Bere ustez, bakoitzaren presentzia fisikoa (jestuak,...), etab. eta kantua bera ezin bereizizkoak dira.

Alta, ohar guzi horiek ohar, argi da grabaketak ahozko tradizioko musikaren azterketari ekarpen anitz egin dizkiola.

Alabaina, soinu-artxiboei esker, emanaldi bat nahi bezainbat aldiz entzuten ahal da, aztertzeko ; eta hori diktaketa bidezko transkripzioarekin ezinezkoa da. Beraz, grabaketei esker, transkripzioa eta/edo analisia aiseago egiten dira.

Bertzalde, grabaketaren bidez, nolabaiteko « kontrola » izan daiteke, a posteriori. Analisi edo transkripzio oro bertze edozein ikerlari edo musikazalek uler edo/eta eztabaida,

24 Beraz, transkripzioa, aitzinetik egin grabaketa bat behin eta berriz entzunez egin notazioa, « jada gertakari baten emaitza denaren emaitza [litzateke]. Eta hastapeneko ele-ekintzatik urruntzen segitzen dugu » (Laborde 1992). 
baiezta edo ezezta dezake ${ }^{25}$. Grabaketak, bertze nornahiri, entzun obra metodo eta tresna ezberdinekin aztertzeko bidea ematen dio; adibidez, bertze parametro batzuetan zentratuz.

Halaber, grabaketaren kalitatea aski ona bada, grabaketaren analisia akustikoa eginez, gogoetak objektibatu daitezke, hipotesiak baieztatu edo ezeztatu, grabaketa arretaz entzunez.

Euskal Herriari buruzko grabaketa-corpusa mende batez baino gehiagoz osatu denez, euskal kantuaren analisia diakronikoa eta sinkronikoa egin daitezke (Hirigoyen Bidart 2012).

Azkenik, ahozko tradizioko musikaren grabaketa edo/eta transmisioa xede dituen desmartxa ororendako, grabaketa tresna ordezka ezina da.

Hala, ene musika doktoregoko tesi aurkezpenean, Xarles Videgain epaimahaikide izateko xantza izan nuen, eta hari eskaintzen diot artikulu hau. Beraz, bururatzeko, bere hitzak hartu nahi nituzke, idatzi honek oinarri baititu. Noiz « sortuko da euskal ahozkotasunaren zentro bat, baliabide handiekin, ahozkoa filologoen zehaztasunarekin landuko lukeena, baina aldi berean testuen errateko baldintzak kontuan hartuz, testu horiek kantatuak izan ala ez, egiazko corpus baten sortzeko? ». Kultura funts hain aberatsa noiz libreki zabalduko eta balioetsiko da, transmititzeko xedearekin? Kultura bat aipatzea, jada biziaraztea baita. Milesker Xarles.

Milesker Nahia Zubeldia-ri itzulpenarendako.

\section{Erreferentziak}

Arana Martija, José Antonio. 1976. Música vasca. San Sebastián : Caja de Ahorros Municipal de San Sebastián. [2/ 1987. Bilbao : Caja de Ahorros Vizcaina]

Arana Martija, José Antonio. 1983. La musique basque. In Jean Haritschelar (dir.), Etre basque, 361-377. Toulouse : Privat.

Arom, Simha. 2002. La trascrizione. In Tullia Magrini (dir.), Universi sonori. Introduzione all'ethnmusicologia, 69-93. Torino : Einaudi.

Azoulay, Léon. 1901. Le Musée phonographique de la Société d'Anthropologie. In Bulletins de la Société d'anthropologie de Paris (2) Vo Série, 327-330. Paris.

Azoulay, Léon. 1902. Liste des phonogrammes composant le Musée phonographique de la Société d'Anthropologie. In Bulletins de la Société d'anthropologie de Paris (3) Vo Série, 652-666. Paris.

Azkue, Resurrección María (de). 1922-1923. Cancionero popular vasco, edición manual, sin acompañamiento. Barcelona. [3/ 1990. Bilbao : Euskaltzaindia]

Bagües, Jon. 2002. La construction des monuments musicaux. In Denis Laborde (dir.), Kantuketan, l'univers du chant basque, 77-98. Donostia : Elkar.

Bartók, Béla. 1956. Pourquoi et comment recueille-t-on la musique populaire?. In Szabolcsi Bence (ed), Bartók sa vie, son cuvre. 164-183. Budapest : Corvina.

25 Angélique Fulinen liburuak (2005), adibidez, desmartxa horiek ahalbidetzen ditu, barnean dakarren CDari esker. 
Bordes, Charles. 1899. La musique populaire des Basques. In Gustave Boucher (dir.), La tradition au Pays Basque, 295-358. Paris : Aux bureaux de la tradition nationale.

Botte, Marie-Claire. 1989. Laudition : système auditif, perception et organisation perceptive élémentaire. In C. Bonnet, R. Ghiglione \& J.-F. Richard (Eds.), Traité de psychologie cognitive, perception, action, langage, 83-127. Paris : Bordas.

Castellengo, Michèle. 1994. La perception auditive des sons musicaux. In Arlette Zenatti (dir.), Psychologie de la musique, 55-86. Paris: Presses Universitaires de France.

Cordereix, Pascal. 2005. Les fonds sonores du département de l'Audiovisuel de la Bibliothèque nationale de France. Le Temps des médias 2/2005 (n 5). 253-264. URL : www.cairn. info/revue-le-temps-des-medias-2005-2-page-253.htm, consulté le 27 mars 2012.

Donostia, Père José Antonio. 1937. La chanson basque et son harmonisation. Bulletin du Musée Basque n 3-4. 67-73. Bayonne: Association des Amis du Musée Basque.

Dutertre, Jean-François. 1991. La voix parmi les recueils. In Collecter la mémoire de l'autre, 1019. Niort : Geste Éditions.

Ellingson, Ter. 1992. Notation. In Helen Myers (dir.), Ethnomusicology, an introduction (1), 153164. London : MacMillan Press.

Frigyesi, Judit. 1999. Transcription de la pulsation, de la métrique et du "rythme libre". In Cahiers de musiques traditionnelles $n^{\circ} 12$ : Noter la musique, 55-73. Genève: Ateliers d'ethnomusicologie.

Fulin, Angélique \& Tehenta. 2005. Matalaz. Le chant basque hier et aujourd'hui. Euskal kantua atzo eta egun. Gotein-Libarrenx : Abotia.

Gallop, Rodney A. 1928. La chanson populaire basque. Bulletin du Musée Basque nº 8. 1-25. Bayonne: Association des Amis du Musée Basque.

Gascue, Francisco. 1913. Orígen de la música popular vascongada. Revista Internacional de estudios vascos $n^{\circ}$ 7-1. 67-98. Paris : RIEV.

Hirigoyen Bidart, Marie. 2012. Le chant basque monodique (1897-1990) : analyse musicologique comparée des sources écrites et musicales. Université Toulouse II le Mirail.

Ithurriague, Jean. 1947. Un peuple qui chante, les Basques. Paris : Edimpress.

Laborde, Denis. 1992. Linvention d'une tradition Sü Azia et le chant souletin. Ekaina. Revue d’Etudes Basques n 43. 180-189. Saint-Jean-de-Luz : Ekaina.

Laborde, Denis. 1996. D'Iztueta à Negu Gorriak en passant par Donostia, incessantes fabrications d'une musique basque. Bulletin du Musée Basque n 143. 27-34. Bayonne: Association des Amis du Musée Basque.

Lerchundi, Père Gabriel. 1947. Simples réflexions sur la chanson populaire basque suggérées par la parution du chansonnier « Kantuz » de MM. Les abbés Lafitte et Etchemendy. Eusko Jakintza. 655-677. Bayonne.

Marcel-Dubois, Claudie. 2003. La musique au Pays Basque Français avec audition de disques enregistrés en 1947. In VII ${ }^{\text {èe }}$ Congrès d’Etudes Basques (7. 1948. Biarritz), 21-25. Donostia : Eusko Ikaskuntza.

Michel, Francisque. 1857. Le Pays Basque, sa population, sa langue, ses mours, sa littérature et sa musique. Paris : Firmin Didot frères, fils et cie.

Morel Borotra, Natalie. 2003. L’opéra basque (1884-1937). St-Etienne-de-Baïgorry : Izpegui. 
Navarre, Pierre. 1970. Essor ou déclin de la chanson basque?. Bayonne: Gure Herria.

Oronoz Antxordoki, Belen. 2000. Gazteri berria, Kantagintza Berria. Euskal Kantagintza Berriaren ("Ez dok Amairu») eta Nova Canço Catalana-ren ("Els Setze Jutges») arteko azterketa konparatiboa. Donostia : Erein.

Parejo-Coudert, Raphaël. 2002. Mémoire et dynamique culturelle en pays basque. Les archives sonores basques : recensement, production et projet de phonothèque basque. Bulletin de liaison des adhérents de l'AFAS [En ligne], 23 | automne-hiver 2002. Mis en ligne le 01 octobre 2002, consulté le 27 mars 2012. URL : http://afas.revues.org/393

Perre, Didier \& Le Gonidec, Marie-Barbara. 2013. Chansons et contes de Haute-Loire, L'enquête phonographique de 1946. Édition critique établie par Didier Perre, avec la collaboration de Marie-Barbara Le Gonidec. Paris/Riom : Éditions du C.T.H.S., A.M.T.A.

Verdure, Nicolas. 2006. Les archives de l'enregistrement sonore à la Bibliothèque nationale de France'. Vingtième Siècle. Revue d'histoire 4/2006 (n 92). 61-66. URL : www.cairn. info/revue-vingtieme-siecle-revue-d-histoire-2006-4-page-61.htm consulté le 27 mars 2012.

Will, Udo. 1999. La baguette magique de l'ethnomusicologue. Repenser la notation et l'analyse de la musique. In Cahiers de musiques traditionnelles $n^{\circ} 12$ : Noter la musique, 9-33. Genève : Ateliers d'ethnomusicologie. 